Check for updates

Cite this: Org. Biomol. Chem., 2017, 15, 3152

Received 11th February 2017,

Accepted 10th March 2017

DOI: 10.1039/c7ob00331e

rsc.li/obc

\section{Stereoselective synthesis of novel adamantane derivatives with high potency against rimantadine-resistant influenza A virus strains $\uparrow$}

\author{
Nikolai Yu. Kuznetsov, (D) *a Rabdan M. Tikhov, (D) ${ }^{a}$ Ivan A. Godovikov, ; $^{a}$ \\ Michael G. Medvedev, $\S^{a}$ Konstantin A. Lyssenko, $\S^{a}$ Elena I. Burtseva, ${ }^{b}$ \\ Elena S. Kirillovab and Yuri N. Bubnov*a,c
}

\begin{abstract}
A series of $(R)$ - and $(S)$-isomers of new adamantane-substituted heterocycles (1,3-oxazinan-2-one, piperidine-2,4-dione, piperidine-2-one and piperidine) with potent activity against rimantadine-resistant strains of influenza A virus were synthesized through the transformation of adamantyl-substituted $\mathrm{N}$-Boc-homoallylamines 8 into piperidine-2,4-diones 11 through the cyclic bromourethanes 9 and key intermediate enol esters 10. Biological assays of the prepared compounds were performed on the rimantadineresistant S31N mutated strains of influenza $A-A / C a l i f o r n i a / 7 /$ 2009(H1N1)pdm09 and modern pandemic strain A/IIV-Orenburg/ 29-L/2016(H1N1)pdm09. The most potent compounds were both enantiomers of the enol ester 10 displaying $I_{50}=7.7 \mu \mathrm{M}$ with the 2016 Orenburg strain.
\end{abstract}

Adamantane derivatives have found numerous applications in various fields of chemistry, but their use in catalysis ${ }^{1}$ and medicinal chemistry ${ }^{2}$ has been especially fruitful. With a lowmolecular weight and highly symmetric structure, adamantane fragments provide a domain with critical lipophilicity (with a molecular diameter of $6.36 \AA)^{3}$ when inserted in the structure of known pharmacophores, improving pharmacokinetic profiles of the modified drugs. ${ }^{4}$ Simple aminoadamantanes (amantadine, rimantadine, tromantadine, memantine) (Fig. 1) have occupied a reliable place in the pharmaceutical market,

\footnotetext{
${ }^{a}$ A.N. Nesmeyanov Institute of Organoelement Compounds, Russian Academy of Sciences, Vavilov 28, 119991 Moscow, Russian Federation.

E-mail: nkuznff@ineos.ac.ru

${ }^{b}$ N.F. Gamaleya Institute of Epidemiology and Microbiology, Russian Academy of Medicinal Sciences, Gamaleya 18, 123098 Moscow, Russian Federation

${ }^{c}$ N.D. Zelinsky Institute of Organic Chemistry, Russian Academy of Sciences,

Leninsky pr. 47, 119991 Moscow, Russian Federation

$\dagger$ Electronic supplementary information (ESI) available: Experimental details, copies of the ${ }^{1} \mathrm{H}$ and ${ }^{13} \mathrm{C}$ NMR spectra, HPLC traces, antiviral activity assay and selected crystallographic data. CCDC 1517135-1517137, 1440627 and 1530899. For ESI and crystallographic data in CIF or other electronic format see DOI: 10.1039/c7ob00331e

\$NR experiments.

$\S \mathrm{X}$-Ray diffraction analysis.
}

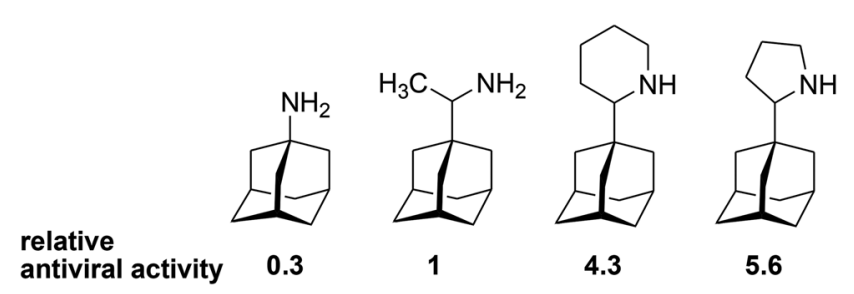

Amantadine Rimantadine

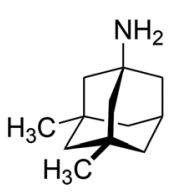

Memantine<smiles>CN(C)CCOCC(=O)NC12CC3CC(CC(C3)C1)C2</smiles>

Tromantadine
Fig. 1 Biologically active aminoadamantanes.

proving their efficiency for the treatment of viral diseases (influenza A, herpes, hepatitis C, HIV) and neurological disorders (Parkinson and Alzheimer diseases). ${ }^{2}$

It is known that piperidine and pyrrolidine derivatives of adamantane (Fig. 1) possess high antiviral activity towards the influenza A virus $\left(\mathrm{A}_{2} / \mathrm{Japan} / 305 / 1957\left(\mathrm{H}_{2} \mathrm{~N}_{2}\right)\right)$, exceeding rimantadine activity by 4.3 and 5.6 times, respectively. ${ }^{5}$ Meanwhile, mutations and evolutionary changes in the influenza A virus have led to the development of $45 \%$ resistance in all the circulating virus strains towards adamantane-based drugs, and the average resistances of the most frequent $\mathrm{H} 1$ and $\mathrm{H} 3$ subtypes were 70\% (years 1933-2013) and 44\% (years 1968-2013), respectively. ${ }^{6}$ Moreover, the temporal distribution of the virus's resistance is alarming; for example, during 2009-2013, the resistance of the H1N1 subtype reached $100 \%$ in many countries. This situation has resulted in a complete ban on the use of rimantadine and amantadine in medical practices. Nevertheless, the comprehensive knowledge concerning the mechanism of the action of aminoadamantanes, as inhibitors of the proton $\mathbf{M}_{2}$ channel of the influenza virus, together with the high pharmaceutical value 


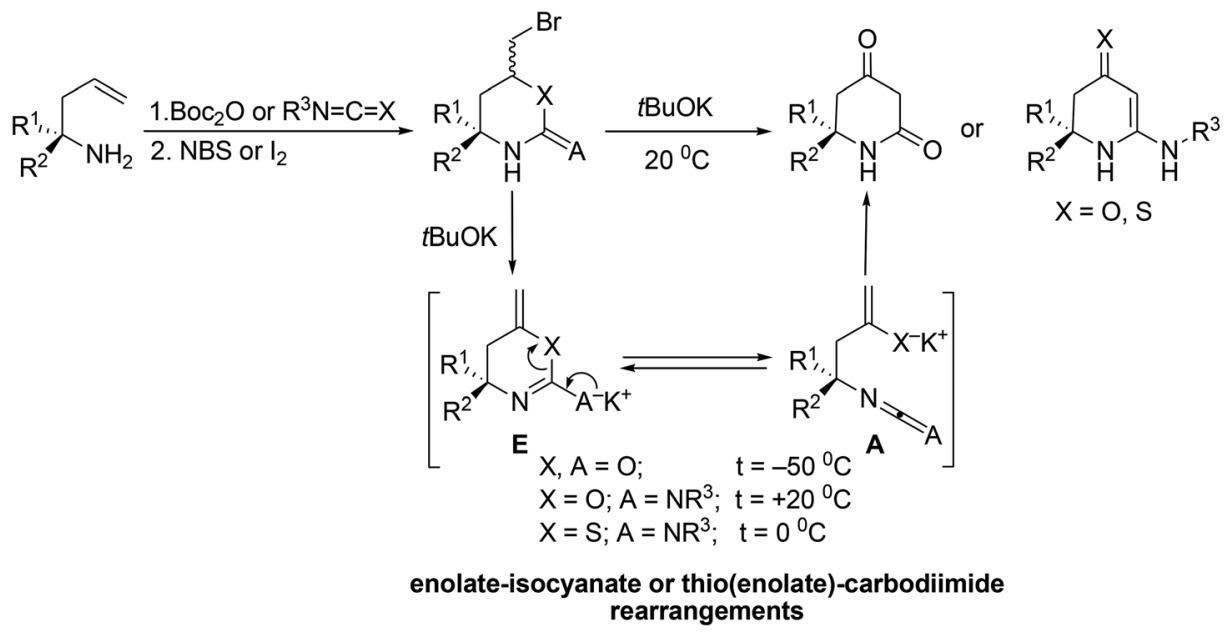

Scheme 1 General scheme and conditions of anionic enolate-type rearrangements.

of adamantane derivatives stimulates research on the synthesis of novel adamantane-containing molecules.

Recently, an efficient stereoselective synthesis route for various substituted piperidin-2,4-diones and related piperidinone-type molecules starting from readily available homoallylamines was developed by our team (Scheme 1). ${ }^{7}$ This approach is based on the anionic enolate-type rearrangements of the cyclic enol esters (E), which are disclosed as the reactive intermediates (A) enolate-isocyanate or enolate-carbodiimide and further cyclized into the corresponding piperidinone-type molecules.

Regarding applications of adamantane chemistry, we were interested in the synthesis of new enantiomerically pure molecules with joint adamantane and piperidinone skeletons in order to evaluate their antiviral activity, which is expected to be higher than that of rimantadine. Previous data obtained in vivo (mice) indicates that both enantiomers of rimantadine are equipotent with the racemic mixture; ${ }^{8}$ however, the recent NMR study of stereoisomers of rimantadine shows their different binding profiles with the $\mathbf{M}_{2}$ virus channel. ${ }^{9}$ The effect of chirality will strengthen with the growth in size of the substituents at the chiral center.

\section{Results and discussion}

Though many adamantane-containing molecules have been synthesized to date, there is still a lack of low-molecular weight adamantanes for modifications and biological tests, especially in an enantiomerically pure form. The presented approach allows access to new chiral adamantanes that were unavailable before. Synthesis of the substituted adamantanes started from the condensation of 1-adamantylcarbaldehyde $\mathbf{1}$ and Ellman's $(R)$ - and $(S)$-sulfinamides $2^{10}$ in a solution of neat $\mathrm{Ti}(\mathrm{OiPr})_{4}$ (5 equiv.) that produced the corresponding imines 3 (Scheme 2 ). Subsequent allylation of the imines 3 was carried out using two different metals, $\mathrm{Zn}$ and In, in THF because the different
Lewis acidity of the zinc and indium allylic reagents usually affected the stereoselectivity of the allylation reaction. ${ }^{11,7 b}$ The obtained diastereomeric ratio in the allylated product $\mathbf{4}$ could not be determined by ${ }^{1} \mathrm{H}$ NMR because only one set of signals with few impurities was observed. Therefore, the sulfinamides 4 through the consecutive desulfination with $\mathrm{HCl}$ and acylation with $\mathrm{Cbz}-\mathrm{Cl}$, were converted to $\mathrm{N}$-Cbz-protected amines $(S)$ - and $(R)-5$, which were suitable for chiral HPLC analysis. For the racemate preparation, chiral sulfoximine $\left(R_{S}\right)-3$ was transformed to achiral sulfonimine 6 through the $m$ CPBA mediated oxidation. Allylation of the latter with AllZnBr gave sulfonamide 7 , which was deprotected by treatment with $\mathrm{TfOH}$ upon mild heating $\left(40 \rightarrow 50{ }^{\circ} \mathrm{C}\right)$. The deprotected racemic amine without isolation was acylated with $\mathrm{CbzCl}$ in a DCM solution in the presence of $20 \% \mathrm{NaOH}$, which afforded rac-5. HPLC analysis of the isomers 5 shows $>99 \%$ ee with $\mathrm{Zn}$ and $97 \%$ ee with In, which evidently corresponds to the diastereoselectivity of the allylation reaction. Sulfinamide $\mathbf{4}$ forms a very stable complex with the In salt, which does not decompose in the conventional workup with a $\mathrm{NH}_{4} \mathrm{Cl}$ solution, and washing the reaction mixture with Trilon $\mathrm{B}$ gives an excellent isolated yield of $4(c a .100 \%)$. The description of the diastereoselectivity models in the allylation reactions can be found in paper ${ }^{7 b}$ and the references therein. Removal of Ellman's auxiliary by treatment of $\mathbf{4}$ with $\mathrm{HCl}$ in $\mathrm{MeOH}$ followed by in situ acylation of the homoallylamine with Boc-anhydride leads to $N$-Boc-derivatives $8(80 \%)$. The absolute $(S)$-configuration of the chiral center in one of the isomers $\mathbf{8}$ was established by X-ray single crystal analysis $((S)-8)$ obtained from $\left(\left(R_{S}\right)-2\right)$ (Fig. $\left.S 1 \dagger\right) .{ }^{12}$ The interaction of 8 with NBS in DCM gave rise to isomeric urethanes 9a (Scheme 3) in the ratio cis/trans $4: 1\left({ }^{1} \mathrm{H}\right.$ NMR, $\mathrm{CDCl}_{3}$ ), and they were not separable by FC. Therefore, the major isomer cis-9a was isolated from the mixture by crystallization from EtOAc, and the relative configurations of the chiral centers were determined by NOESY experiment.

Upon treatment of the mixture of cis/trans-isomers 9a with $t$ BuOK $\left(25^{\circ} \mathrm{C}, 30 \mathrm{~min}\right)$, an expected dione $\mathbf{1 1}$ was formed in a 


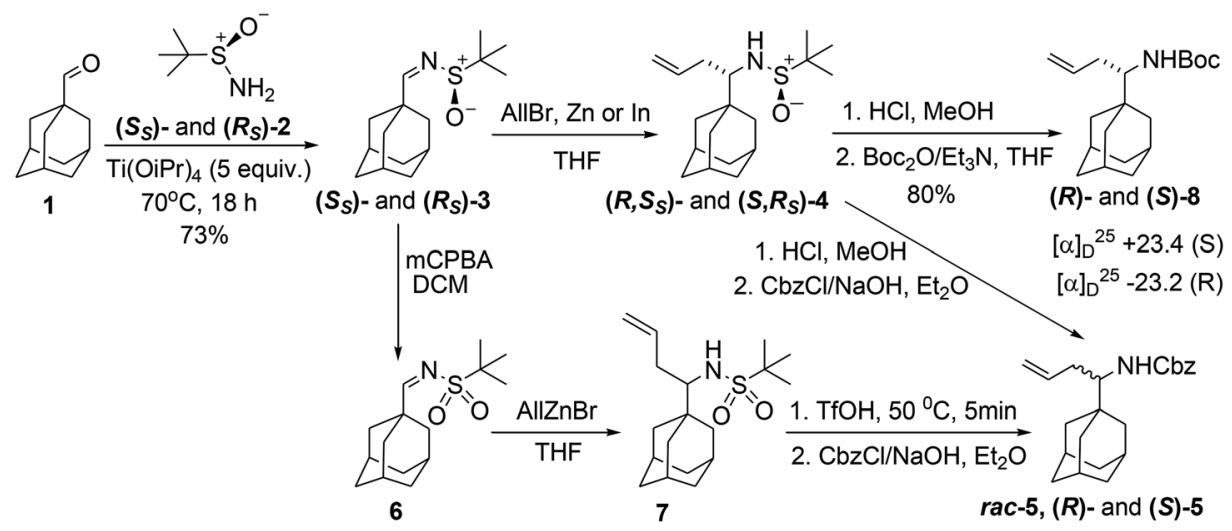

\begin{tabular}{|c|c|c|}
\hline Metal & Time, $\mathrm{h}$ & ${\text { Yield; } d . \mathrm{e}^{\mathrm{a}}, \mathrm{\%}}^{\mathrm{Z}}$ \\
\hline $\mathrm{Zn}$ & 0.5 & $\mathbf{4}, 95 ;>99$ \\
\hline $\mathrm{In}$ & 18 & $\mathbf{4}, \sim 100 ; 97$ \\
\hline $\mathrm{Zn}$ & 0.5 & $\mathbf{7}, 98$, rac $^{\mathrm{b}}$ \\
\hline
\end{tabular}

a) according to HPLC of 5 ; b) only one chiral centre

Scheme 2 Synthesis of both (S)- and (R)-8 and standards 5 for HPLC analysis.

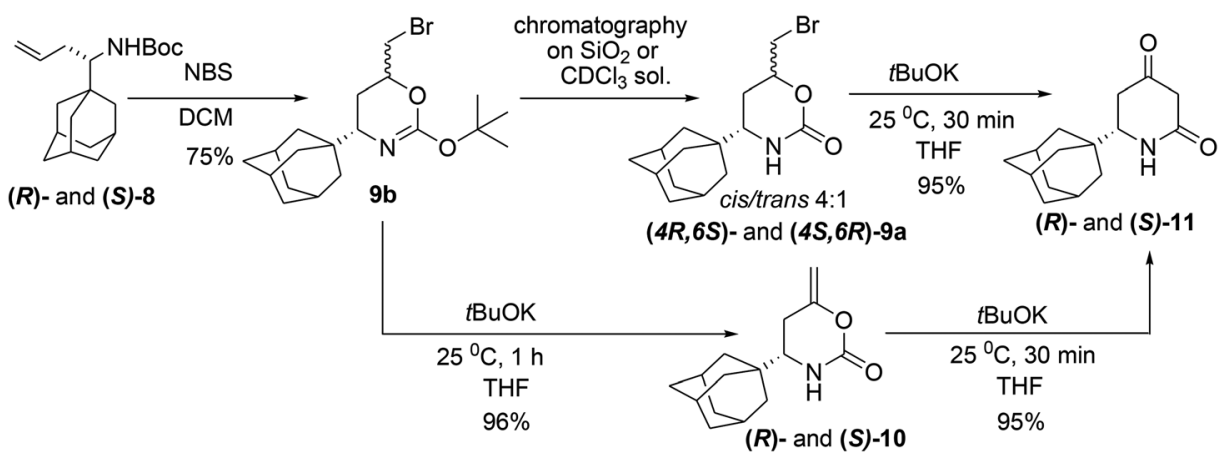

Scheme 3 Synthesis of of both (S)- and (R)-isomers of enol ester 10 and dione 11.

high yield. However, during repetition of the experiments, we observed that together with 11, a cyclic enol ester 10 was formed, and its amount changed widely in a range of $20-90 \%$. Actually, $\mathbf{1 0}$ is an intermediate and cannot be isolated under usual conditions because the transformation of $\mathbf{1 0}$ into $\mathbf{1 1}$ occurs even at $-50{ }^{\circ} \mathrm{C}$ (Scheme 1$)^{7 a}$ and is much faster than the elimination of $\mathrm{HBr}$ from 9a. In the preceding papers devoted to enolate-carbodiimide rearrangement, ${ }^{7 c}$ we observed the formation of some enol esters as intermediates with substrates bearing $N$-EWG-groups, but in the case of the enolatecarbodiimide rearrangement, this is possible because of the low rate of the reaction (Scheme 1). Considering the possible methods of ester $\mathbf{1 0}$ survival, we concluded that the reactivity can be affected by an intermolecular association of the molecules into dimeric complexes where the $\mathrm{NH}$-protons are shielded from the attack of $t \mathrm{BuOK}$ by voluminous adamantane groups. The XRD of $(S)$-10 supported our hypothesis (Fig. 2). ${ }^{12}$ In the crystals, two independent molecules $(S)-\mathbf{1 0}$ are

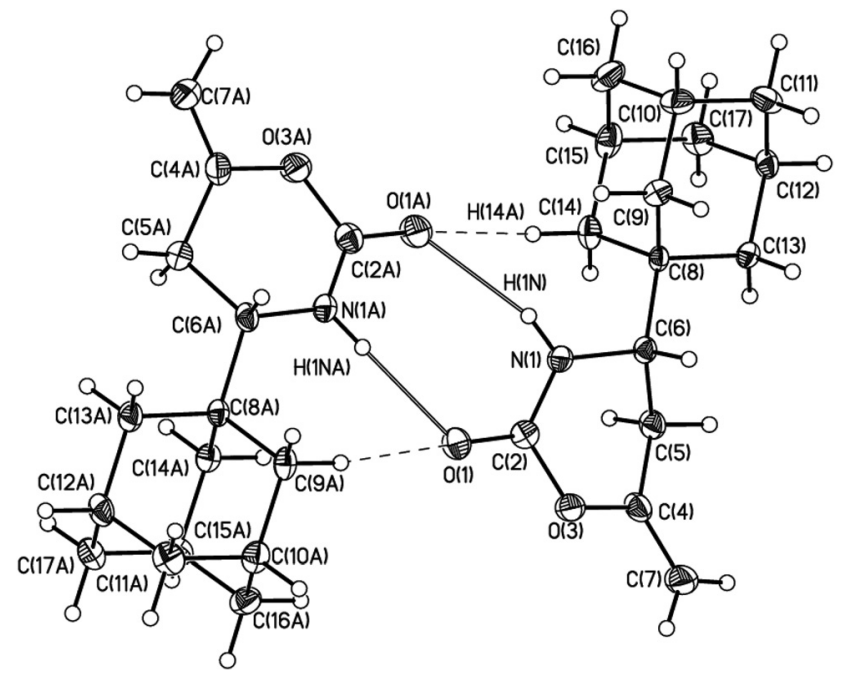

Fig. 2 The general view of hydrogen bonded molecules in the crystal of (S)-10 in the representation of atoms by thermal ellipsoids ( $p=50 \%$ ). 
assembled into homochiral dimers due to the typical $\mathrm{N}-\mathrm{H} \cdots \mathrm{O}$ (N...O 2.935(2)-2.973(2) §) hydrogen bonding of the lactame groups that are additionally stabilized by the $\mathrm{C}-\mathrm{H} \cdots \mathrm{O}(\mathrm{H}(9 \mathrm{AA})$ ..O (1) 2.36, $\mathrm{H}(14 \mathrm{~A}) \cdots \mathrm{O}(1 \mathrm{~A}) 2.46 \AA$ ) interactions formed with the adamantyl substituents occupying the pseudoequatorial position. The distances between the nonbonded atoms, $\mathrm{H}(9 \mathrm{AA}) \cdots \mathrm{HN}(1 \mathrm{~A}) 2.15 \AA$ 足 $\mathrm{H}(14 \mathrm{~A}) \cdots \mathrm{HN}(1) 2.23 \AA$, are generally less than the sum of the van der Waals radii of the hydrogen atoms, thus, the NH-protons can be shielded by adamantane from the base attack. For the analysis of the intermolecular interactions, QTAIM theory ${ }^{13}$ was used. This theory gives an opportunity to locate all the bonding interactions by a critical point search as well as estimating the energy of the interactions by means of the Espinosa correlation. ${ }^{14}$ The electron density function in the crystal was obtained by means of a recently introduced concept of invarioms, ${ }^{15}$ and the accuracy of this approach for the estimation of weak and moderate strength hydrogen bonds was recently verified. ${ }^{16}$

However, our attempts to reveal the existence of the dimers in a DMSO-D ${ }_{6}$ solution by ${ }^{1} \mathrm{H}$ DOSY experiments were unsuccessful. Finally, we disclosed that the enol ester $\mathbf{1 0}$ arises only if the reaction mixture of $\mathbf{8}$ and NBS was not purified by conventional chromatography and was only filtered through the short pad of the silica gel or not purified at all. We proposed the formation of the cyclic tert-butyl ether $\mathbf{9 b}$, in which $\mathrm{HBr}$ elimination would proceed more readily. ${ }^{7 a}$ An analysis of the proton spectrum of the crude reaction mixture in $\mathrm{C}_{6} \mathrm{D}_{6}$, after passing through the $0.5 \mathrm{~cm}$ thickness layer of silica gel, has shown that the mixture consists of two isomers of tert-butyl ether $\mathbf{9 b}$. For analytical purposes, the major isomer cis-9b was isolated by crystallization from cooled hexane, and its structure was studied by XRD (Fig. S2 $\dagger$ ). This product was very sensitive to acids and immediately decomposed into 9a on silica gel TLC, FC or in a solution of $\mathrm{CDCl}_{3}$, so its discovery was a lucky circumstance. In fact, using two types of isolation procedures for bromides $\mathbf{9 a , b}$, flash chromatography or short pad filtration, we were able to synthesis both enantiomers of either enol ester $\mathbf{1 0}$ or dione $\mathbf{1 1}$ in preparative quantities. The molecular structure of $(R)-\mathbf{1 1}$ was also studied by XRD. ${ }^{12}$ In the crystal of $\mathbf{1 1}$ in contrast to 10, the amide groups assemble molecules into infinite chains in which molecules are assembled by $\mathrm{N}-\mathrm{H} \cdots \mathrm{O}\left(7.12 \mathrm{kcal} \mathrm{mol}^{-1}\right)$ and $\mathrm{C}-\mathrm{H} \cdots \mathrm{O}$ (0.7-1.91 kcal mol ${ }^{-1}$ ) bonds (Fig. S3†). The 4-keto-group in 11 was diastereoselectively reduced with $\mathrm{NaBH}_{4}$ (Scheme 4), which is known to produce excellent cis/trans selectivity $\mathrm{dr}=$ $32: 1$ for the reduction of the 6-phenyl-substituted dione. ${ }^{17}$
In our case, the diastereomeric ratio of the 6-(1-adamantyl)substituted alcohols 12 formed upon the action of $\mathrm{NaBH}_{4}$ at $-78^{\circ} \mathrm{C}$ was only $10: 1$, and upon decreasing the reaction temperature to $-90{ }^{\circ} \mathrm{C}$, alcohols 12 with $\mathrm{dr}=17: 1$ were obtained in the best experiment (because of the heterogeneity of the reaction mixture, diastereoselectivity value was vary in different experiments at the same conditions). In the crystal of alcohol $(4 R, 6 R)-12$, the presence of the $\mathrm{OH}$-group leads to principally different crystal packing patterns with participation of $\mathrm{OH}$ groups of two independent molecules in hydrogen bonding with the $\mathrm{NH}(\mathrm{C}=\mathrm{O})$ function (Fig. $\mathrm{S} 4 \dagger) .{ }^{12}$ The mixture of diastereomeric alcohols $\mathbf{1 2}$ was further subjected to a reduction with 5 equiv. of $\mathrm{LiAlH}_{4}$; however, surprisingly, even after prolonged heating $(24 \mathrm{~h})$ in THF, 12 was returned without changes. Adamantane-derivative $\mathbf{1 2}$ has demonstrated distinct behavior from other 6-substituted piperidine-2-ones, which are usually readily reduced with $\mathrm{LiAlH}_{4}$ to piperidines. ${ }^{18}$ The reduction of the lactame group in $\mathbf{1 2}$ can be blocked by the formation of some aggregates similar to the dimeric complexes observed in crystals of $\mathbf{1 0}$. On the other hand, the $\mathrm{BH}_{3}{ }^{*} \mathrm{SMe}_{2}$ complex, which is less sterically demanding than the solvated $\mathrm{LiAlH}_{4}$, reduces lactame 12 easily to give 4-hydroxypiperidine 13 in a high yield (85\%) after FC. Aminoalcohols 13 were converted to hydrochlorides by treatment with ethereal $\mathrm{HCl}$ followed by recrystallization from the EtOAc/MeOH mixture that gave diastereomerically pure hydrochlorides $\mathbf{1 3}$.

Having in hand a set of enantiomerically pure adamantyl substituted piperidines $\mathbf{9 a - 1 3}$, we undertook a study of their antiviral properties. A mechanism of anti-influenza A activity of amantadine and rimantadine was studied in detail and it was found to be mainly related to blocking of the proton channel $\mathbf{M}_{2}$ of the influenza A virus. A comprehensive study of a protein complex of the tetrameric $\mathbf{M}_{2}$ channel with amantadine and rimantadine by high-resolution NMR as well as crystallographic methods has revealed two types of blocking mechanisms. A main mechanism is considered to be "sterical blocking”, wherein a drug molecule acts as a stopper in a bottle neck inside the channel of $\mathbf{M}_{2}$, and this mechanism operates with a minimal amount of the aminoadamantane inhibitor (ratio Ad: $\mathbf{M}_{2}=1: 1$ ). ${ }^{19}$ Another possibility for the channel binding is the interaction of aminoadamantane with the outer side of the tetrameric channel $\mathbf{M}_{2}$ (ratio Ad: $\mathbf{M}_{2}=$ $4: 1$ ) in pockets formed by the hydrophilic part of Asp 44 and hydrophobic residues of Leu 40, Ile 42 and Leu 43. Such binding reduces the mobility of the protein chains and stabilizes the closed form of the $\mathbf{M}_{2}$ channel. In the case of amanta-

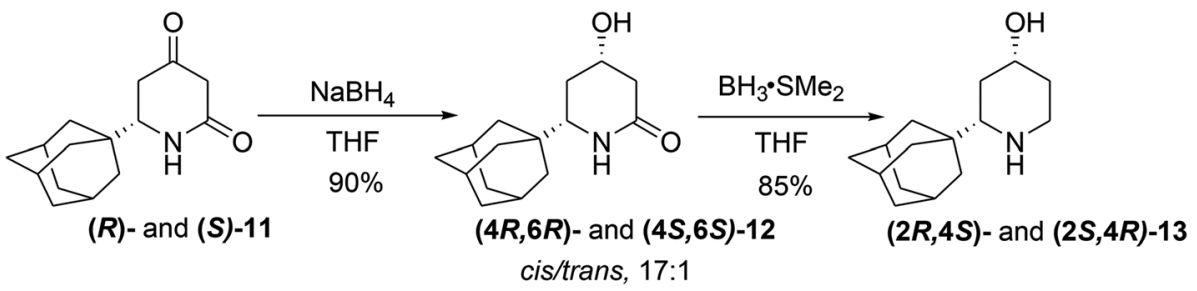

Scheme 4 Stereoselective synthesis of hydroxypiperidines. 
dine, the position in the channel lumen is more preferable (40 fold greater affinity) than the peripheral site. ${ }^{19}$ As we mentioned above, a majority of the contemporary virus strains is resistant to the adamantane-type $\mathbf{M}_{2}$ channel inhibitors because of the so-called S31N mutation. ${ }^{20}$ In recent years, considerable progress was achieved in designing potent inhibitor molecules that target the $\mathbf{M}_{2}$ channel of drug resistant influenza A viruses. ${ }^{21,22}$ The most potent inhibitors of $\mathrm{M}_{2} / \mathrm{S} 31 \mathrm{~N}$ mutants were aminoadamantanes-based molecules, such as 2-propyl-2-aminoadamantane, ${ }^{22 a}$ pyrimidine-(pyridine-)substituted adamantanes ${ }^{22 b}$ and isoxazole-containing molecules. ${ }^{22 c, d}$ Since the $\mathrm{A} / \mathrm{M}_{2}-\mathrm{S} 31 \mathrm{~N}$ mutant is one of the most conserved viral proteins among the current influenza A viruses, with more than $95 \%$ of the virus carriers, S31N mutated etalon pandemic strain of influenza virus A/California/7/2009(H1N1)pdm09 and modern A/IIV-Orenburg/29-L/2016(H1N1)pdm09 were selected as targets for tests. The tests were performed in the infected cells of MDCK tissue, and the values on the suppression of the virus reproduction are presented in Table 1.

The activity of all the synthesized compounds considerably exceeds that of rimantadine. The most expected 4-hydroxy-substituted analogues of adamantyl-piperidine (Fig. 1) show moderate activity $(2 R, 4 S)-\mathbf{1 3}$ with an $\mathrm{IC}_{50}=18.4$ and $17.6 \mu \mathrm{M}$, and its enantiomer $(2 S, 4 R)-\mathbf{1 3}$ is almost two times less active with an $\mathrm{IC}_{50}>40.0 \mu \mathrm{M}$ (California) and $26.9 \mu \mathrm{M}$ (Orenburg). Both isomers of the lactames $\mathbf{1 2}$ have low activities, close to the activity of $(2 S, 4 R)-\mathbf{1 3}$. Both isomers of dione $(R)$ - and $(S)$-11 have lower values of $\mathrm{IC}_{50}=20.6,26.7 \mu \mathrm{M}$ (California) and 27.1, $34.0 \mu \mathrm{M}$ (Orenburg) than those of $(2 R, 4 S)-13$; however, they have a more effective inhibition profile because the $\%$ of suppression of virus replication reaches higher values, 72.5 and $82.5 \%$ relative to 53 and $27 \%$ for $(2 R, 4 S)-13$ (Table 1 ). The most potent were isomers of the enol ester 10 with $\mathrm{IC}_{50}=8.1$ for $(R)-\mathbf{1 0}$ and $\mathbf{1 3 . 7}$ for $(S)$-10 with complete suppression of virus reproduction from $30 \mu \mathrm{M}$. Interestingly, that Orenburg mutant strain became less sensitive to all compounds except the isomers of the enol ester 10 with an $\mathrm{IC}_{50}=7.7 \mu \mathrm{M}$ and a high suppression activity reaching $94-96 \%$ at C $30 / 40 \mu \mathrm{M}$ (Table 1). Enol ester 10 can be even more potent than we observed because the performed stability test in the MEM medium disclosed that the half-life of $\mathbf{1 0}$ is $\mathbf{7 . 4 4}$ hours at a temperature of virus incubation $\left(37^{\circ} \mathrm{C}\right)$. Though the MEM medium has a $\mathrm{pH}$ around neutral, 10 can rearrange into dione 11 (Schemes 1 and 3) under alkaline $\mathrm{pH}$ in aqueous solution. Bromo-derivatives 9a were also quite active in the suppression of the California strain with an $\mathrm{IC}_{50}=19.8$ and $11.3 \mu \mathrm{M}$ for $(4 S, 6 R)$ - and $(4 R, 6 S)-9 \mathrm{a}$, respectively. Generally $(R)$-isomers were more potent as inhibitors of $\mathbf{M}_{2}$ channels independent of the other structural variations that support the recent NMR study on the rimantadine enantiomers. ${ }^{9}$ The cytotoxicities of the synthesized compounds are comparable to the value of rimantadine (Table 1), and the most active isomers of the enol ester $\mathbf{1 0}$ were also more toxic to MDCK cells. However, the values of $\mathrm{IC}_{50}$ for the isomers $\mathbf{1 0}$ are considerably lower than the corresponding values of $\mathrm{TCD}_{50}$.

One conclusion about the mechanism of antiviral action can be drawn from our data. Different from known aminoadamantanes with antiviral activity to $\mathrm{A} / \mathrm{M}_{2}-\mathrm{S} 31 \mathrm{~N}$ mutants, ${ }^{21,22}$ our compounds are not basic (except of 13) and cannot act through the suggested alternative mechanisms connected with the changing $\mathrm{pH}$ value. At the same time, all molecules follow the uniform dependence of activity on concentration. It is very probable that the mechanism of their antiviral action is also similar and related to the binding of the $\mathrm{M}_{2}$ channel.

In conclusion, we have demonstrated the antiviral effect on the mutated virus strains by action of very simple molecules with close structures to the known aminoadamantanes with known binding places in and on the $\mathbf{M}_{2}$ channel. It is not known in which site the enol ester 10 binds, but acquiring this knowledge is important for the development of next generation anti-influenza A agents. A compact and rigid structure of the adamantane-derived 6-membered heterocycles has the potential for modification and provides an excellent opportu-

Table 1 Suppression of the reproduction of an etalon pandemic strain of influenza virus A/California/7/2009 (H1N1)pdm09 and modern pandemic strain A/IIV-Orenburg/29-L/2016 (H1N1)pdm09 in the cells of MDCK tissue with cytotoxicity values

\begin{tabular}{|c|c|c|c|c|c|c|c|}
\hline \multirow[b]{3}{*}{ Compound } & \multicolumn{6}{|c|}{$\%$ of suppression of virus strains of (H1N1)pdm09 ${ }^{a}$} & \multirow[b]{3}{*}{$\mathrm{TCD}_{50}, \mu \mathrm{M}$} \\
\hline & \multicolumn{2}{|c|}{ A/California/7/2009 } & \multirow[b]{2}{*}{$\mathrm{IC}_{50}, \mu \mathrm{M}$} & \multicolumn{2}{|c|}{ A/IIV-Orenburg/29-L/2016 } & \multirow[b]{2}{*}{$\mathrm{IC}_{50}, \mu \mathrm{M}$} & \\
\hline & $30 \mu \mathrm{M}^{c}$ & $40 \mu \mathrm{M}^{c}$ & & $30 \mu \mathbf{M}^{c}$ & $40 \mu \mathrm{M}^{c}$ & & \\
\hline$( \pm)$-Rimantadine & $\mathrm{NA}^{b}$ & $\mathrm{NA}^{b}$ & - & $\mathrm{NA}^{b}$ & $\mathrm{NA}^{b}$ & - & $>300$ \\
\hline$(4 S, 6 R)-9 \mathbf{a}$ & 62.7 & 70 & 19.8 & 67.8 & 69 & 21.9 & $>300$ \\
\hline$(4 R, 6 S)-\mathbf{9 a}$ & 71.6 & 73 & 11.3 & 72.2 & 74 & 20.1 & $>300$ \\
\hline$(R)-10^{d}$ & 97.9 & 99.9 & 8.1 & 94.7 & 95.9 & 7.7 & 80 \\
\hline$(S)-\mathbf{1 0}^{d}$ & 99.2 & 100 & 13.7 & 94 & 91.8 & 7.7 & 80 \\
\hline$(R)-\mathbf{1 1}$ & 68 & 72.5 & 20.6 & 57.5 & 69.9 & 27.1 & 80 \\
\hline$(S)-\mathbf{1 1}$ & 58 & 82.5 & 26.7 & 46.3 & 54.9 & 34.0 & 160 \\
\hline$(4 R, 6 R)-12$ & 21.9 & 39.5 & $>40.0$ & 38.6 & 42.6 & $>40.0$ & $>300$ \\
\hline$(4 S, 6 S)-\mathbf{1 2}$ & 16.4 & 17.4 & $>40.0$ & 36.6 & 40.2 & $>40.0$ & $>300$ \\
\hline$(2 R, 4 S)-13$ & 51 & 53 & 18.4 & 55 & 57 & 17.7 & 150 \\
\hline$(2 S, 4 R)-13$ & 32 & 27 & $>40.0$ & 52 & 53 & 26.9 & 150 \\
\hline
\end{tabular}

${ }^{a}$ The values obtained upon simultaneous addition of inhibitors and virus. ${ }^{b}$ No activity. ${ }^{c} \%$ of suppression of the reproduction of the influenza A virus at 30 and $40 \mu \mathrm{M}$ (average value). ${ }^{d}$ Half-life time of 10 in the MEM medium; $T_{1 / 2}=7.44 \mathrm{~h}$ at $37{ }^{\circ} \mathrm{C}$ (see ESI file). 
nity for further research in various fields of adamantane chemistry, including drug discovery.

\section{Acknowledgements}

This work was financially supported by the Russian Science Foundation (grant no. 15-13-00109). The authors are grateful to Dr S. Lubimov for chiral HPLC analysis.

\section{References}

1 K. A. Agnew-Francisa and C. M. Williams, Adv. Synth. Catal., 2016, 358, 675-700.

2 (a) L. Wanka, K. Iqbal and P. R. Schreiner, Chem. Rev., 2013, 113, 3516-3604; (b) T. P. Stockdale and C. M. Williams, Chem. Soc. Rev., 2015, 44, 7737-7763.

3 N. Moreldesrosiers and J. P. Morel, J. Solution Chem., 1979, 8, 579-592.

4 Brain-directing properties: (a) N. Tsuzuki, T. Hama, M. Kawada, A. Hasui, R. Konishi, S. Shiwa, Y. Ochi, S. Futaki and K. Kitagawa, J. Pharm. Sci., 1994, 83, 481-484; (b) Z. Kazimierczuk, A. Gorska, T. Switaj and W. Lasek, Bioorg. Med. Chem. Lett., 2001, 11, 1197-1200; (c) K. Kitagawa, N. Mizobuchi, T. Hama, T. Hibi, R. Konishi and S. Futaki, Chem. Pharm. Bull., 1997, 45, 1782-1787. Gene delivery: (d) M. Manoharan, K. L. Tivel and P. D. Cook, Tetrahedron Lett., 1995, 36, 3651-3654. Enzyme activity: (e) N. D. Igumnova, E. Lemina, I. I. Bitiukova, N. V. Klimova and A. P. Skoldinov, Farmakol. Toksikol., 1988, 51, 38-41; $(f)$ D. J. Augeri, J. A. Robl, D. A. Betebenner, et al., J. Med. Chem., 2005, 48, 5025-5037.

5 G. Stamatiou, G. B. Foscolos, G. Fytas, A. Kolocouris, N. Kolocouris, C. Pannecouque, M. Witvrouw, E. Padalko, J. Neyts and E. De Clercq, Bioorg. Med. Chem., 2003, 11, 5485-5492.

6 G. Dong, C. Peng, J. Luo, C. Wang, L. Han, B. Wu, G. Ji and H. He, PLoS One, 2015, 10, e0119115.

7 (a) N. Yu. Kuznetsov, V. I. Maleev, V. N. Khrustalev, A. F. Mkrtchyan, I. A. Godovikov, T. V. Strelkova and Yu. N. Bubnov, Eur. J. Org. Chem., 2012, 334-344; (b) N. Yu. Kuznetsov, V. N. Khrustalev, T. V. Strelkova and Yu. N. Bubnov, Tetrahedron: Asymmetry, 2014, 25, 667-676; (c) N. Yu. Kuznetsov, R. M. Tikhov, I. A. Godovikov, V. N. Khrustalev and Yu. N. Bubnov, Org. Biomol. Chem., 2016, 14, 4283-4298; (d) N. Yu. Kuznetsov, R. M. Tikhov, T. V. Strelkova, Yu. N. Bubnov and K. A. Lyssenko, Tetrahedron Lett., 2016, 57, 4525-4528.

8 P. E. Aldrich, E. C. Hermann, W. E. Meier, M. Paulshock, W. W. Prichard, J. A. Snyder and J. C. Watts, J. Med. Chem., 1971, 14, 535-543.

9 A. K. Wright, P. Batsomboon, J. Dai, I. Hung, H.-X. Zhou, G. B. Dudley and T. A. Cross, J. Am. Chem. Soc., 2016, 138, 1506-1509.

10 M. T. Robak, M. A. Herbage and J. A. Ellman, Chem. Rev., 2010, 110, 3600-3740.
11 X.-W. Sun, M.-H. Xu and G.-Q. Lin, Org. Lett., 2006, 8, 4979-4982.

12 CCDC 1440627, $(S)-8 ;$ 1530899, 9b; 1517135, $(S)-\mathbf{1 0}$; 1517136, $(R)$-11 and 1517137, $(4 R, 6 R)$-12. Experimental data contain in the supplementary crystallographic data for this paper. The principal bond lengths and angles in complexes studied are also given in ESI. $\dagger$

13 (a) E. Espinosa, E. Molins and C. Lecomte, Chem. Phys. Lett., 1998, 285, 170-173; (b) E. Espinosa, I. Alkorta, I. Rozas, J. Elguero and E. Molins, Chem. Phys. Lett., 2001, 336, 457-461.

14 R. F. W. Bader, Atoms In molecules. A Quantum Theory, Clarendron Press, Oxford, 1990.

15 B. Dittrich, T. S. Koritsansky and P. Luger, Angew. Chem., Int. Ed., 2004, 43, 2718-2721.

16 (a) Y. V. Nelyubina, A. A. Korlyukov and K. A. Lyssenko, Chem. - Eur. J., 2014, 20, 6978-6984; (b) Y. V. Nelyubina and K. A. Lyssenko, Chem. - Eur. J., 2015, 21, 9733-9741.

17 F. A. Davis, T. Fang, B. Chao and D. M. Burns, Synthesis, 2000, 2106-2112.

18 (a) A. J. Burke, S. G. Davies, A. C. Garner, T. D. McCarthy, P. M. Roberts, A. D. Smith, H. Rodriguez-Solla and R. J. Vickers, Org. Biomol. Chem., 2004, 2, 1387-1394; (b) Y. Yang, D. P. Phillips and S. Pan, Tetrahedron Lett., 2011, 52, 1549-1552; (c) Y. Xie, A. Raffo, M. Ichise, S. Deng, P. E. Harris and D. W. Landry, Bioorg. Med. Chem. Lett., 2008, 18, 5111-5114.

19 S. D. Cady, K. Schmidt-Rohr, J. Wang, C. S. Soto, W. F. DeGrado and M. Hong, Nature, 2010, 463, 689-693.

20 (a) R. J. Garten, et al., Science, 2009, 325, 197-201; (b) A. Antóna, F. Pozoc, J. Niubód, I. Casasc and T. Pumarolaa, Enferm. Infecc. Microbiol. Clin., 2012, 30(Supl. 4), 10-17.

21 Reviews: (a) J. Wang, F. Li and C. Ma, Biopolymers, 2015, 104, 291-309; (b) Z. Shena, K. Loua and W. Wang, Acta Pharm. Sin. B, 2015, 5, 419-430.

22 (a) A. Kolocouris, C. Tzitzoglaki, F. B. Johnson, R. Zell, A. K. Wright, T. A. Cross, I. Tietjen, D. Fedida and D. D. Busath, J. Med. Chem., 2014, 57, 4629-4639; (b) F. Li, C. Ma, Y. Hu, Y. Wang and J. Wang, ACS Infect. Dis., 2016, 2, 726-733; (c) F. Li, C. Ma, W. F. DeGrado and J. Wang, J. Med. Chem., 2016, 59, 1207-1216; (d) F. Li, Y. Hu, Y. Wang, C. Ma and J. Wang, J. Med. Chem., 2017, 60, 15801590; (e) V. A. Shibnev, T. M. Garaev, M. P. Finogenova, E. S. Shevchenko and E. I. Burtseva, Pharm. Chem. J., 2012, 46, 3-7; $(f)$ P. G. Deryabin, T. M. Garaev, M. P. Finogenova, A. G. Botikov and V. A. Shibne, Bull. Exp. Biol. Med., 2014, 157, 62-65. Examples of inhibitors $\mathrm{A} / \mathrm{M}_{2}$ ineffective against S31N mutants: $(g)$ S. Wu, et al., ChemMedChem, 2015, 10, 1837-1845; (h) M. Rey-Carrizo, E. Torres, C. Ma, M. BarniolXicota, J. Wang, Y. Wu, L. Naesens, W. F. DeGrado, R. A. Lamb, L. H. Pinto and S. Vázquez, J. Med. Chem., 2013, 56, 9265-9274; (i) M. Rey-Carrizo, M. Barniol-Xicota, C. Ma, M. Frigolé-Vivas, E. Torres, L. Naesens, S. Llabrés, J. Juárez-Jiménez, F. J. Luque, W. F. DeGrado, R. A. Lamb, L. H. Pinto and S. Vázquez, J. Med. Chem., 2014, 57, 5738-5747. 